\title{
IMPLEMENTATION OF LEAN CONSTRUCTION AS A SOLUTION FOR THE COVID-19 IMPACTS IN RESIDENTIAL CONSTRUCTION PROJECTS IN LIMA, PERU
}

\author{
Daniel Verán-Leigh ${ }^{1}$ and Xavier Brioso ${ }^{2}$
}

\begin{abstract}
At the beginning of 2020, a virus discovered in the province of Wuhan in China identified as SARS- COV-2, denominated COVID-19, began to spread globally, being identified by the World Health Organization (WHO) as a pandemic on March 13 since the epidemic has spread to several countries in all the continents and affects a large number of people (WHO 2020). In Peru the entry of COVID-19 caused the Peruvian government to take different options to control its spread such as mandatory quarantines and lockdowns. In front of this scenario, the Architecture Engineering and Construction (AEC) sector had to reinvent itself since it is a sector where work depends on a significant amount of personnel (IPE 2020). Furthermore, the level of industrialization in Peru is significantly lower compared with industrialized countries, generating that the consumption of labor is greater as well as the cost of the project, searching for new solutions to improve productivity. Moreover, considering the new sanitary measures for COVID-19 including new health protocols, controls, and improvement of working sanitary standards. Therefore, the main purpose of the present paper is to present a planning proposal for a system that integrates the Lean tools and the COVID-19 protocol for armed concrete buildings in Peru and present the preliminary results of its modification on the production system, design of work schedules, planning meetings, among other aspects of the construction system.
\end{abstract}

\section{KEYWORDS}

COVID-19, lean construction, Last Planner® System, construction system.

\section{INTRODUCTION}

The construction industry production has grown just $1 \%$ per year over the past 2 decades and is reflected in the lagging productivity, combined skilled labor shortages, and unpredictable materials cost, leads to low projects performance, over budget, and times of execution more than planned (McKinsey \& Company 2020).

Related to the construction sector in Peru, affected by the COVID-19 pandemic, reduced its productivity by $15.6 \%$ during 2020 (La Republica 2019, Veran-Leigh et al. 2019). Nevertheless, it is considered to increase to $17.4 \%$ in 2021 and $4 \%$ in 2022

1 Chief Construction Engineer, VyV Bravo Construction Group. GETEC Research Group and PELCAN Research Group, Pontifical Catholic University of Peru Lima, Peru, daniel.veran@pucp.pe, orcid.org/0000-0002-6174-2054

2 Professor, GETEC Research Group, Department of Engineering, Pontifical Catholic University of Peru, Lima, Peru, xbrioso@ pucp.edu.pe, orcid.org/0000-0002-0174-0241 
according to the Central Reserve Bank of Peru (El Peruano 2020). In response to the high expectations of recovery in the construction sector in the next years, the use of different construction methods and philosophies such as Lean Construction (LC), have been implemented to enhance construction systems, with the main goal of improving competitiveness and performance (Alarcon 1997, Ghio 2001, Cho and Ballard 2011).

Furthermore, the pandemic has highlighted the importance of the physical proximity and level of human interactions across occupations, including the construction sector. Considering this one as an on-site field job, the use of remote work does not work efficiently and is unproductive for the sector, considering the face-to-face construction works and constant communication within the project for each of the specialties involved (McKinsey \& Company 2021). Is in this scenario where the implementation of new construction systems, technology and procedures using the new sanitary protocols for the control of the workforce become a must in every construction project that requires a significant amount of manpower to carry out day-to-day jobs (Fischer et al. 2017, McKinsey \& Company 2020).

According to the Peruvian scenario, the story starts at the end of May 2020 when the Peruvian state established the beginning of the fourth phase of reactivation with the opening of economic activities related to construction, transport, mining, among others (MINSA 2020). This restart of construction activities was first linked to the preparation of a COVID-19 protocol by each construction company, then once the projects restarted, problems such as COVID-19 tests, contagion control, the amount of available trained workforce, among others problems, became recurrent (MVCS 2020). To control them and improve the procedures, the implementation of the Lean Construction Philosophy (LCP), became a possible solution to continue the processes and be able to move the project forward. Therefore, the main purpose of the present work is to present a planning proposal for a system that integrates the Lean tools and the COVID-19 protocol for armed concrete buildings in Peru and present the preliminary results of its application in a building project.

\section{COVID-19 PROTOCOLS IN THE CONSTRUCTION SECTOR}

The construction sector globally had to implement new security and COVID-19 control protocols. The similarity that occurs in first world countries such as the United States of America (USA) as well as in Latin American countries such as Peru, Chile, and Colombia, was the implementation of security protocols, entry of personnel, control of exposure risk levels, standard operating procedures, reduction of staff, implementation of teleworking and teleconferences to reduce as much as possible the approachement between workers, among other variables (BID 2020, United States Department of Labor 2020).

The cessation of works at the national level from the beginning of the pandemic until thereactivation of phase 4 in June 2020. Starts with the presentation of the COVID-19 Resumption plan to the Peruvian Ministry of Health (MINSA), where the following information was presented: a descriptive report of the project, current state of the work stations, modifications in the health protocols to comply with the new COVID-19 Protocol, work fronts (sectorizations), amount of personnel by work areas, disinfection and collective biosafety protection, the staff distribution and comorbidity screening. This information was presented and aligned with the ministerial Resolution 448-2020 in June 2020 (MINSA 2020) and the newest document presented in February 2021 (MINSA 2021). 


\section{LEAN CONSTRUCTION, LAST PLANNER® SYSTEM AND SAFETY MANAGEMENT}

$\mathrm{LC}$ is a way to design a production system to minimize waste of materials, time and effort to generate the maximum possible amount of value. Additionally, the lean tools have the next benefits: organize the project system, work areas, productivity, reduce waste, increase added value, improve occupational health, among other benefits. (Howell et al. 2017). LC contains five main principles used to gain maximum benefit from the system: specify a value for the customer, identify value stream, make value flow without interruptions, let the customer pull value from the producer and pursue perfection (Bertelsen \& Koskela 2004). Furthermore, safety management is considered as one of the chronic problems in construction and LC can contribute to this area by the standardization and systematized production that leads to better safety in the project by having less material in the work area, have the workplace orderly and clean, less confusion in a systematized workflow and fewer disturbances (Koskela 1992). There are several tools and techniques used in LC, such as Last Planner® System (LPS), first-run studies, 5S, fail-safe for quality and Safety and Takt time planning (Koskela et al. 2002, Porwal et al. 2010).

On the one hand, LPS, considered as a collaborative, commitment-based planning system that integrates should-can-will-did planning (Seed 2020). Moreover, the LPS includes the planning cycle divided in four different levels; the master schedule, the phase schedule, look ahead planning (LAP) and the weekly work plan (WWP). The LPS is focused on the reduction of uncertainty and variability in a project workflow, including the management tools of Plan Percent Complete (PPC) to measure the system performance defined according to Ballard et al. (2007a) as "the number of completions divided by the number of assignments for a given week" and the Cause of Non-Compliance (CNC) that can be obtained by performing a root cause analysis to identify the source of action or event chain to learn how repeated failures can be prevented (Ballard 2000, Orihuela 2011, Kassab 2020). Furthermore, contracts with subcontractors and stakeholders are key drivers for participation and attendance in Pull Planning (PP) sessions (Murguia et al. 2016).

On the other hand, the lean safety management system is based on creating an environment in a workplace where there is employee motivation and reliable management. All the different levels of an organization need to put forth their best efforts on a day-today basis and work together toward achieving improved performance and reducing waste. 5S (Sort, set in order, Sweep, Standardize, Sustain) is one of the most effective tools of LC because it is the basis for an effective Lean Implementation (Anvari et al. 2011). Moreover, $5 \mathrm{~S}$ is a method for the cleanup and organization of the workplace and it has been developed in Japanese just-in-time manufacturing and has been used in the implementation of the construction sector. Furthermore, the $5 \mathrm{~S}$ process is a structured program to systematically achieve total organization, neatness, cleanliness, standardization and discipline in the workplace (Lein et al. 2014).

In addition, the LPS recommends: (1) producing collaborative planning including the participation of support areas, like safety and health, (2) identifying and enforcing the adequate anticipation of the constraints, among others (Brioso 2011). Additionally, a case study shows that several tools from LC are related to some of the more common practices implemented even now in the Safety Management System (Antillon et al. 2011). 


\section{RESEARCH METHOD}

Based on the information presented before, the following method of integration on site of the use of lean tools was proposed in conjunction with the new preventive measures of the COVID-19 protocol in Peru. The case of analysis of the impact of the COVID-19 in the construction work will be a project of 18 floors, 4 basements, and common areas of residential housing in Lima, Peru.

Firstly, the COVID-19 implementation plan at work is divided in 5 parts: the modification of changing rooms according to the new distancing and physical separation protocols, relocation of the dining room and common areas, installation of disinfection points at the entrance of the project and in common areas near the changing rooms, expansion of bathrooms and general disinfection of work biweekly (see Figure 1).

The implementation of LC, in the security and production areas, was modified due to the implementation of the COVID-19 protocols. Initially, the use of 5S for the COVID-19 context was presented as a solution for the reorganization of the common areas of the workers. On the other hand, the production system for the design of the flows, the Takt Time Planning (TTP) also known in Peru as a train of activities, like other location-based planning methods, schedules the use of construction workspace along with the time (Pons \& Perez 2019, Singh et al. 2020) was used in the project in the Pre pandemic context and now is modified by the COVID-19 protocols. New restrictions were presented compared to before COVID-19 including: reduction of the sectorization due to the fulfillment of the number of personnel for the type of construction, problems related to the supply of materials by suppliers affected by problems of importing materials, and the increase in the time of the entry of personnel in a staggered and controlled manner due to the protocols of the COVID-19 surveillance plan.

To control the advancement of personnel, before the pandemic there was a sectorization by workgroups for different work items: steel installation, formwork work and concrete pouring. These crews have throughput and a daily work lot. The project had been using the Last Planner® System before the start of the pandemic including the analysis of the cause of non-compliance and analysis of restrictions. Because of the COVID-19 pandemic, the maximum number of people per $\mathrm{m}^{2}$ that could be in the sectors was calculated and the areas of each sector were reduced by $20 \%$ to reduce the number of personnel per work zone. With the new health protocols, productivity was modified and there were different restrictions and causes of non-compliance.

\section{ANALYSIS OF RESULTS}

After the implementation, the on-site work was restarted. These had modifications such as the entry of medical personnel into the project due to the new regulations and the number of personnel, taking rapid COVID-19 tests for the detection of IGG and IgM antibodies or serological tests, COVID-19 training talks (see Figure 1), and restarting work on pouring concrete in the tower. This restart came hand in hand with problems such as sources of contagion, public transport strikes, cessation of metropolitan transportation services, among other factors (El Comercio 2020).

The MINSA approved the use of rapid tests and that workers were only allowed to enter to work if they had tested with negative IGG and IGM results. The problem with this criterion was that it limited enough personal entry to work since there were records of up to $33 \%$ of positives in personnel who went on to do a COVID-19 test since most of them having IGG (who presented antibodies) could not enter until coming out on the negative 
test. Likewise, comorbidity medical examinations were carried out, affecting the number of personnel on-site because those with comorbidities such as hypertension, obesity, diabetes, or those over 60 years of age could not work on the projects, making it difficult to find skilled labor.

The modifications related to the safety in the construction security system apart from the COVID-19 implementation presented the following differences compared to the previous security system including: reduction of capacity in the dining and changing rooms, the use of personal chemical barriers (Alcohol) and more disinfection points. Related to sustainability and safety, minimize the use of disposable bottles and disposable containers to control the entry of personal meals. The prohibition of not leaving organic residues onsite, the order in the use of cleaning areas based on cleaning shifts, and tool washing points.

The solutions that were implemented on-site to be able to maintain production were several, these include the installation of a temporary ladder in the rear area to reduce the flow of personnel, avoiding having a single transit point. In this way, the probability of contagion was significantly reduced, considering that the work was in the hull stage with the beginning of finishes (masonry) and there were more than 100 people on site (see Figure 1).
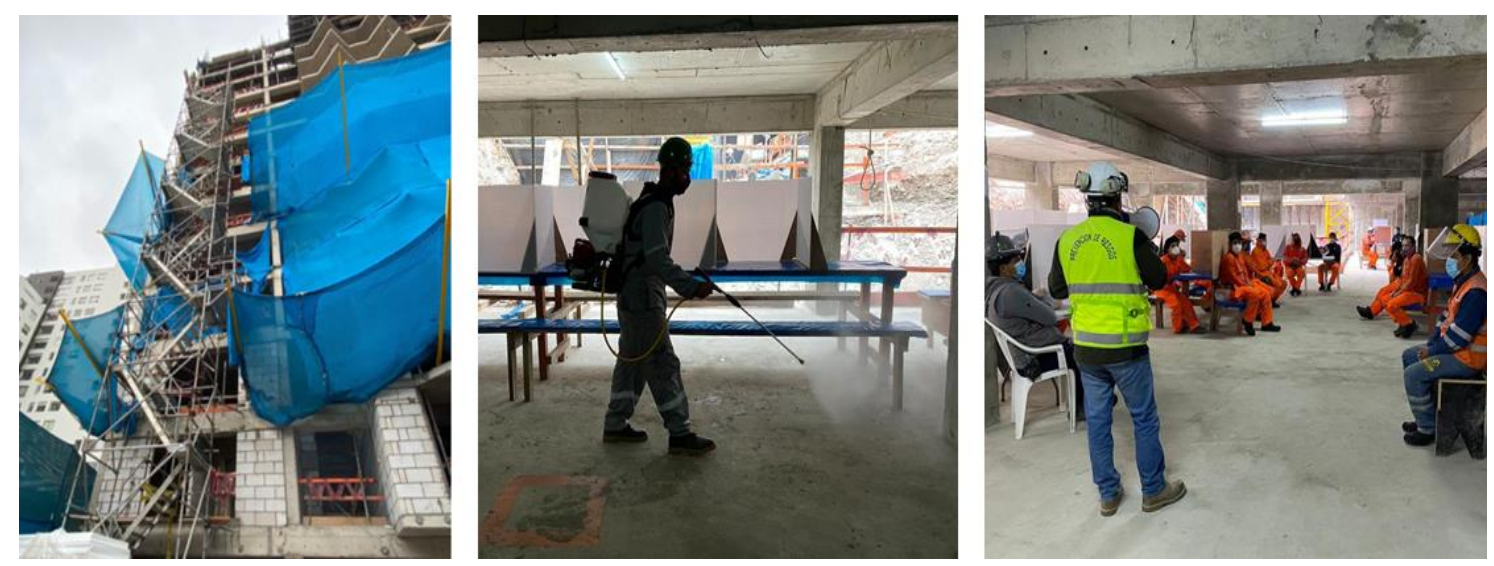

Figure 1: Location of the second access ladder to reduce the flow of work personnel, Disinfection common areas and COVID-19 diary training

Moreover, related to the tower production, according to the TTP method, LPS and COVID19 protocol the sectors were reduced from 4 to 5 . To control the performance of labor as can be seen in Figure 2, sectorization reduced the advance by $20 \%$ in productivity, but the performance of the personnel and the control of the COVID-19 advance could be maintained, complying with the minimum distance of the personnel. 


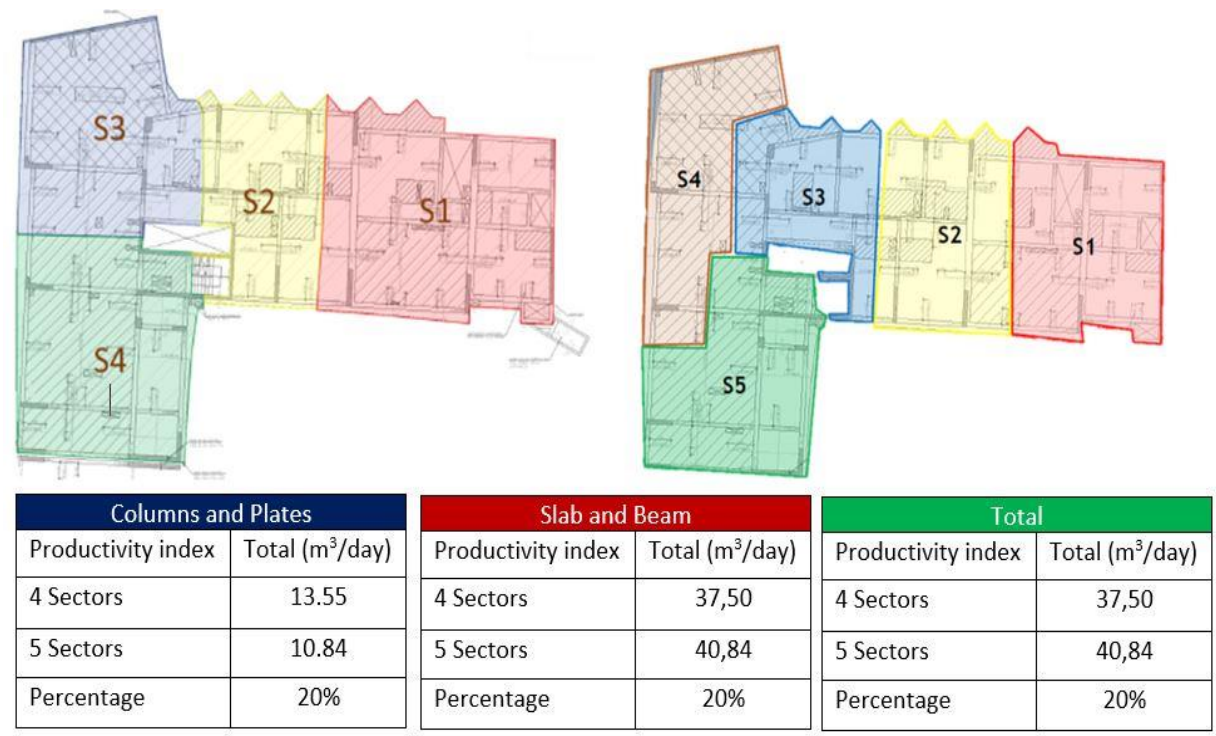

Figure 2: Initial and final sectorization of the project in the helmet stage, with 4 and 5 sectors according to the COVID-19 scenario

On-site control of progress and personnel was done by the use of LC tools such as LAP, PP, Gemba walk, among others. In figure 3 is presented the use of LPS. Furthermore, we have seen that the implementation of LPS before and after the pandemic obtain positive results in the organization, planification and control of the project. Integrating the COVID protocols were detected new restrictions in the execution of the projects as a sanitary safety control, sectorization, efficient workspace distribution and useful work area. In addition, the planning and control tools included COVID-19 measures. For example, the meetings were held with all COVID-19 control protocols, virtual meetings with contractors were implemented to have the only and necessary direct contacts. Daily health awareness talks were held to staff and the entry of staff and contractor companies was stricter according to the new COVID-19 guidelines.
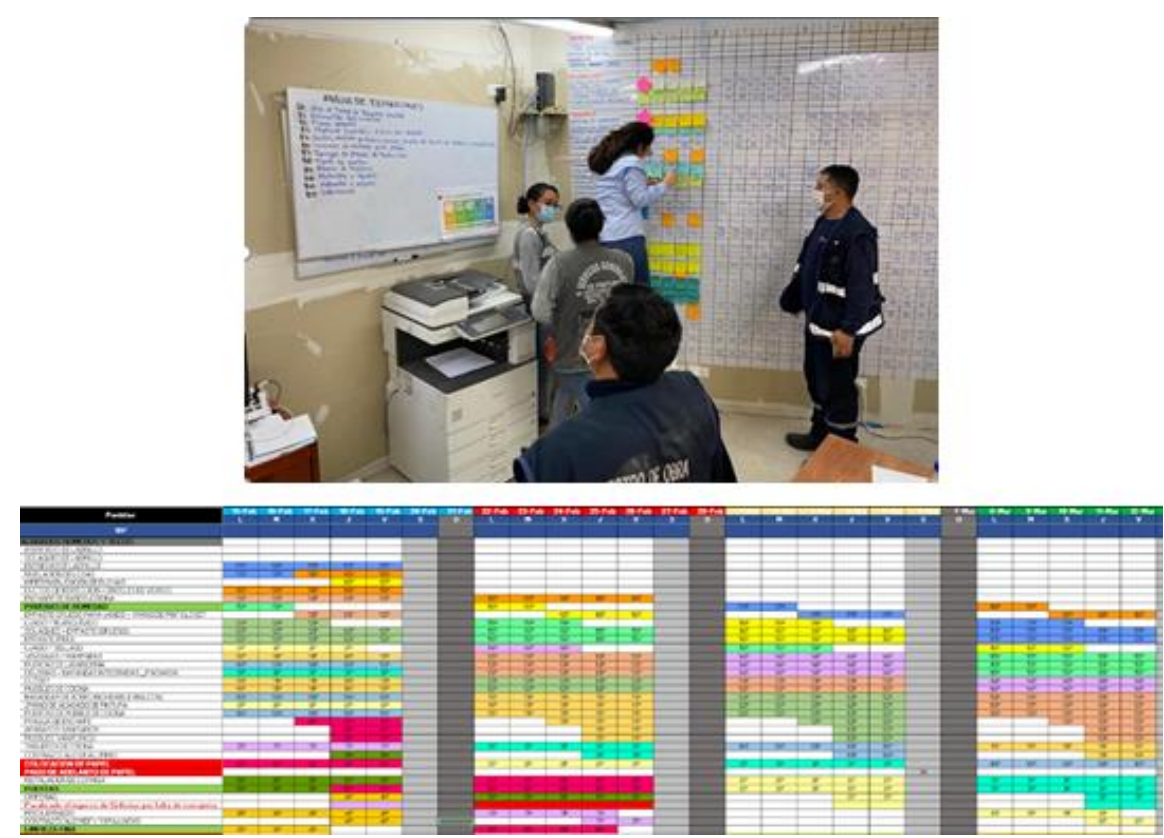

Figure 3: Implementation of Look ahead planning in the week-control and the planification of 4 weeks ahead. 
The PP activity, phase planning, was carried out differently from that implemented in previous stages such as hull and excavation. Each person had their materials (post-its, markers, mandatory disinfection alcohol, among others). It was accomplished by working in open and ventilated offices with compliance with the use of the COVID-19 Personal Protect Equipment (PPES). In this way it was possible to have the work planning, taking into account the experience of the foremen, the team coordination and identifying the material and personnel constraints for each item. Figure 5 is presented ahead. Furthermore, the use of Gemba Walk, a technique used to observe and understand how work is being performed (Dalton 2019), was applied with the entire engineering staff, the superintendence area and the project manager of the real estate agency. To make a team tour, among all the interested parties, to be able to review the work area at the time of the work, resolve doubts about details, progress, be informed of all of the flow of activities and incidents of the work, among other benefits that together in the field could be appreciated.
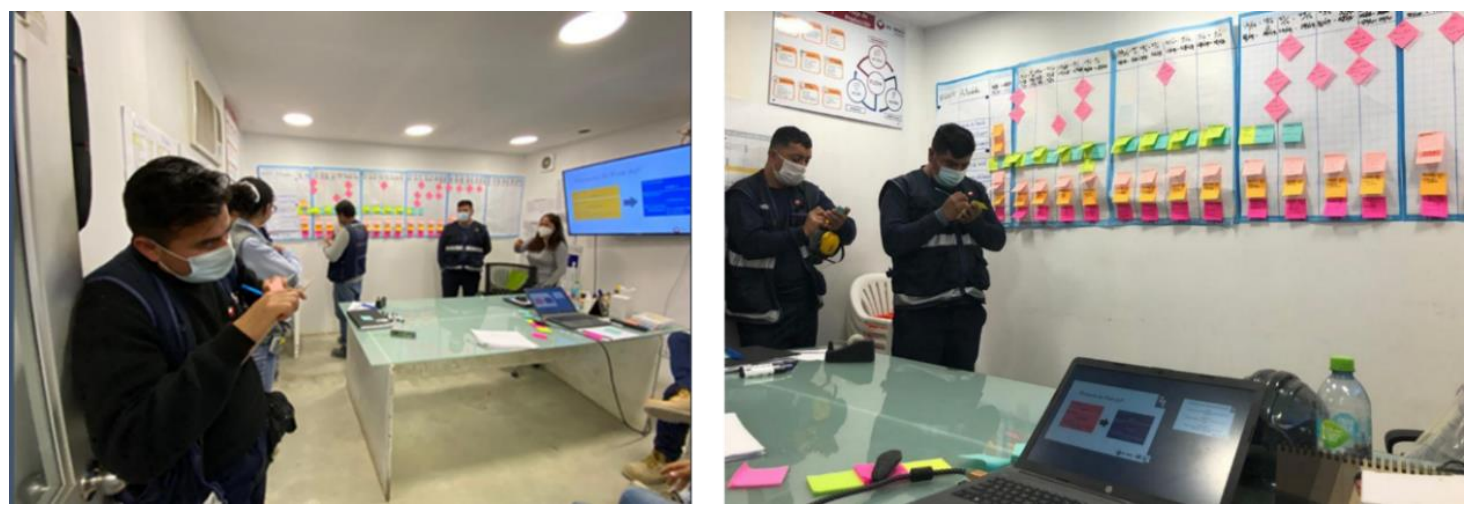

Figure 5: Pull Planning on-site with the project team

To date, the civil construction stage of the project has ended and the finishing stage of the project has been completed. The following analysis is presented using the LCP of CNC and PPC of the studied project. In the analysis presented in Figures 6 and 7, the following can be seen. The PPC during the pandemic was lower compared to the pre-pandemic PPC (4-5\%). In addition, the CNC was greater in the Post-Pandemic stage compared to the previous one due to the insert of the external causes related to the COVID-19. For the Control of the PPC and the CNC was used the software POWER BI of Microsoft (Aspin 2016). Moreover, in the analysis of the results of the implementation of the COVID-19 protocols, stakeholders concluded that the implementation of lean tools such as PP and WWP served to comply with the COVID-19 protocols. Given that in these meetings served for planning and coordinate the work, solutions, provisions and regulations of all the personnel, so that everyone agrees, maintains the same rules and thus complies with the protocols correctly. 


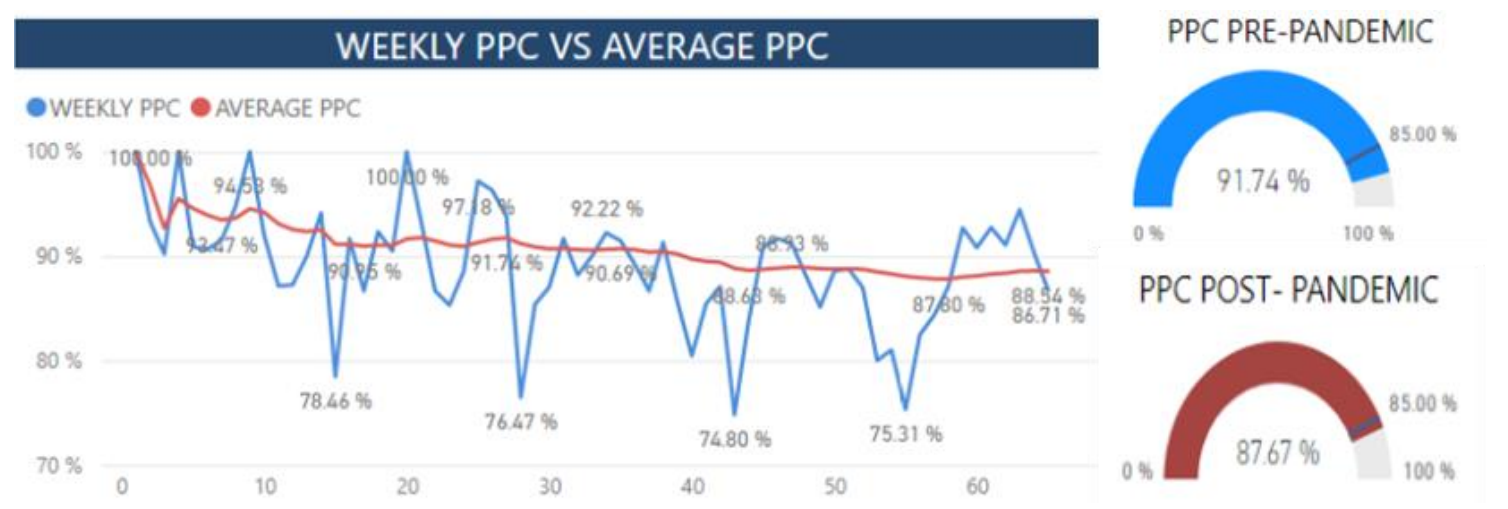

Figure 6: Plan Percent Complete in the residential studied project.

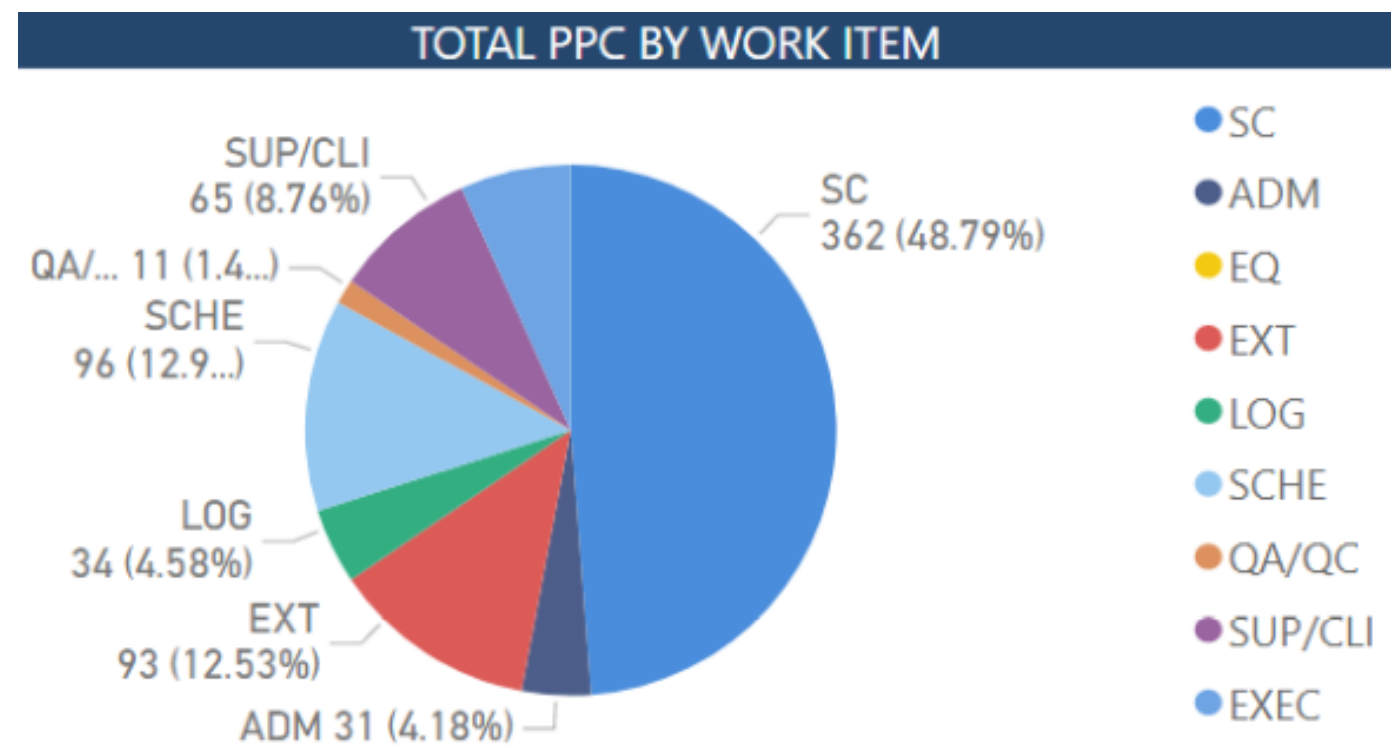

Figure 7: Cause of non-compliance in the residential studied project

However, it is important to mention that the stages in which COVID-19 appeared are different. On the one hand, the Pre COVID-19 scenario was in the structural period, where the participation of interested parties is lower compared to the architectural stage where the number of people, companies, and restraints is greater, which was directly linked to the CNC. Likewise, it is important to emphasize that to date, almost $12.53 \%$ of CNC were generated by external causes (COVID-19) due to: number of infected, personnel with medical rest, difficulty in finding trained personnel, delay in the dispatch of materials from abroad (mainly from China), among other factors. In addition, it is important to consider that the use of PPC and the CNC helped us to be able to identify problems in advance, to be able to solve them and identify the restraints raised and avoid stopping the workflow. Besides, the use of the LCP served to maintain communication between staff to be able to map the infected staff, restraints, and emergency work plans.

\section{CONCLUSIONS}

We can conclude that the impact of COVID-19 in the construction sector was significant during 2020 and at the beginning of 2021, largely modifying security controls, work priorities, construction processes, and control methodologies. On the one hand, it eliminated several companies that did not comply with the appropriate security standards, secure protocols, are informal, among others. Nevertheless, on the other hand, it is 
important to consider that, COVID-19 was an accelerator of the sector in the face of productivity and the implementation of technologies in the sector, driven by social distancing and the need to find new processes. Also, the implementation of new philosophies such as LC for the control, planning, and execution of work turned out to be a successful option to be able to maintain productivity in the residential studied project, complying to date with the deadline, cost, safety, and quality required in the project.

\section{REFERENCES}

Alarcón, L. (1997). "Lean construction”. CRC Press.

Antillon, E. I., Alarcon, L. F., Hallowell, M. R. \& Molenaar, K. R. 2011, “A Research Synthesis on the Interface Between Lean Construction and Safety Management" In: Rooke, J. \& Dave, B., 19th Annual Conference of the International Group for Lean Construction. Lima, Peru, 13-15 Jul 2011.

Anvari, A., Zulkifli, N., Yusuff, R. M. (2011). Evaluation of approaches to safety in lean manufacturing and safety management systems and clarification of the relationship between them. World Applied Sciences Journal, 15(1), 19-26.

Aspin, A. (2016). Pro Power BI Desktop. Apress.

Banco Interamericano de Desarrollo (BID). (2020). El impacto de la crisis del coronavirus en el sector de la construcción pública.

Bertelsen, S., \& Koskela, L. (2004, August). Construction beyond lean: a new understanding of construction management. In Proceedings of the 12 th annual conference in the International Group for Lean Construction.

Brioso, X. (2011), 'Applying Lean Construction to Loss Control ' In: Rooke, J. \& Dave, B., 19th Annual Conference of the International Group for Lean Construction. Lima, Peru, 13-15 Jul 2011.

Cho, S., \& Ballard, G. (2011). Last Planner and Integrated Project Delivery. Lean Construction Journal.

Dalton, J. (2019). Gemba walks. In Great Big Agile (pp. 173-174). Apress, Berkeley, CA.

Diario La República. (2019). La productividad de la construcción es solo del $20 \%$.

El Peruano (2020). Sector construcción se recupera y prevén un avance significativo el 2021. Revista: El Peruano, Lima, Perú.

El Comercio (2020). Paro de transportistas: el minuto a minuto de la suspensión del transporte público que afecta a Lima y el Callao. Revista: El Comercio, Lima, Perú.

Fischer, M., Ashcraft, H. W., Reed, D., \& Khanzode, A. (2017). Integrating project delivery. John Wiley \& Sons.

Ghio Castillo, Virgilio. "Productividad en obras de construcción; Diagnóstico, crítica y propuesta". Lima: Fondo editorial PUCP. 2001.

Instituto Peruano de Economía (IPE). (2020). Señales de un sector en construcción.

Glenn Ballard. "The last planner system of production control". [Tesis doctoral]. Birmingham: Universidad de Birmingham, Facultad de Ingeniería. 2000.

Howell, G., Ballard, G., \& Demirkesen, S. (2017, July). Why lean projects are safer. In Proceedings of the 25th Annual Conference of the International Group for Lean Construction, Heraklion, Greece (pp. 4-12).

Kassab, O. A., Young, B. K., \& Lædre, O. (2020). Implementation of Last Planner® System in an infrastructure project.

Koskela, L., Howell, G., Ballard, G., \& Tommelein, I. (2002). The foundations of lean construction. Design and construction: Building in value, 291, 211-226. 
Koskela, L. (1992). Application of the new production philosophy to construction (Vol. 72). Stanford: Stanford university.

Leino, A., Heinonen, R., \& Kiurula, M. (2014). Improving safety performance through 5s program. In Proc 22nd Ann Conf of the Int'l Group for Lean Construction.

McKinsey Global Institute (2021). The Future of work after COVID-19.

McKinsey \& Company (2020). Rise of the platform era: The next chapter in construction technology.

McKinsey \& Company (2020). The next normal in construction.

Ministerio de Salud (MINSA). (2020). Resolución Ministerial N ${ }^{\circ} 448-2020 / M I N S A$ Lineamientos para la vigilancia, prevención y control de la salud por exposición al SARS-CoV-2.

Ministerio de Salud (MINSA). (2021). Resolución Ministerial N $^{\circ}$ 972-2020/MINSA Lineamientos para la vigilancia, prevención y control de la salud por exposición al SARS-CoV-2.

Ministerio de Vivienda, Construcción y Saneamiento (MVCS). (2020). Resolución Ministerial No 087-2020 Protocolo Sanitario Sectorial (07 de mayo de 2020).

Murguía, D., Brioso, X. \& Pimentel, A. 2016, 'Applying Lean Techniques to Improve Performance in the Finishing Phase of a Residential Building' In:, 24th Annual Conference of the International Group for Lean Construction. Boston, Massachusetts, USA, 20-22 Jul 2016.

Orihuela, Pablo y Ulloa, Karen. "La planificación de las obras y el sistema last planner". Boletín N 12, Corporación aceros Arequipa, julio. 2011.

Pons Achell, J. F., Rubio Pérez, I. (2019). Lean Construction y la planificación colaborativa. Metodología del Last Planner® System.

Porwal, V., Fernandez-Solis, J., Lavy, S., and Rybkowski, Z. 2010. "Last planner system implementation challenges" Proc. 18th Annual Conf. Int. Group for Lean Constr., Technion, Haifa, Israel, 548-556.

Seed. W.R. (2000) "Don't Conform, Transform! A Guide to Better Project Outcomes, Narrated by a Pioneering Leader" Lean Construction Institute.

Singh, V. V., Tommelein, I. D., \& Bardaweel, L. (2020). Visual tool for workload leveling using the work density method for takt planning. In Proceedings of the 28th Annual Conference of the International Group for Lean Construction (IGLC28), Berkeley, CA. doi (Vol. 10, No. 2020, p. 0061).

United States Department of Labor (2020). COVID-19 - Control and Prevention Construction Work.

Verán-Leigh, D., Larrea-Gallegos, G., \& Vázquez-Rowe, I. (2019). Environmental impacts of a highly congested section of the Pan-American highway in Peru using life cycle assessment. The International Journal of Life Cycle Assessment, 24(8), 1496-1514.

World Health Organization. (2020). Coronavirus disease ( COVID-19). 